\title{
The Remediation of Oil Contaminated Soil in Kuwait
}

\author{
Reem Al-Othman ${ }^{1}$, Meshari Al-Bader¹, Alberto De La Roche', Muthanna Al-Mumin ${ }^{1}$, Hussam Sarahney ${ }^{2}$ \\ ${ }^{1}$ Author, Kuwait Oil Company \\ Ahmadi, Kuwait \\ rothman@kockw.com;mabader@kockw.com \\ ${ }^{2} \mathrm{PMC}$, WorleyParson \\ Ahmadi, Kuwait \\ Hussam.Sarahney@WorleyParsons.com
}

\section{Extended Abstract}

This paper describes KERP planned strategy and actual works conducted to remediate 26 million cubic meters of contaminated soil in North and South Kuwaiti Oil Fields after the aggressive Iraqi invasion in 1992. KERP remediation strategy has been modified based on comprehensive Site Soil Characterization (SSC) reports of Consortium of International Consultants (CIC 2003); which was verified through special SSC works completed in North and south Kuwait Excavation and Transportation Projects (NKE\&T and SKE\&T) and various KERP related SSC activities ${ }^{(1)}$. The strategy modification involves reducing landfill volume to less than 5.0 million $\mathrm{m} 3$ by implementing comprehensive remediation techniques which include natural degradation of residual contamination of Tarcrete at TPH levels of 1-2\%, bio-treatment at 2-7\%, remediation technologies at 7-20\%, re-use of high energetic good quality oil and sludge at high TPH levels of 10-20\% and landfilling of difficult to treat soil. Best available and approved technologies combined with best feasible and cost-effective technologies drive the remediation strategy listed above. ${ }^{4}$ KERP contaminated features consist of Dry and Wet Oil Lakes, Contaminated Piles, Tarcrete, WHPs, and Coastal Trench and Deposits. The last two features were totally remediated by excavating, transporting and disposal of the contaminated soil in newly constructed landfills in the south and north Kuwait through NKE\&T and SKE\&T Projects. However, Tarcrete physical and chemical characteristics revealed no toxicity, fragile, dry, and thin crust feature with no harm to exclude from remediation program. The Program tackled several challenges related to $100 \%$ UXO survey and clearance, climate conditions limiting working hours, and spread of contamination over huge areas, as well as executing the site works with massive earth movement equipment and personnel from various subcontractors is a challenge itself ${ }^{(2,3)}$. However, collaborative efforts of various stockholders such as KOC, SRP-II, SRS, PMC, local contractors, and KNFP are minimizing risks during the execution ${ }^{(4)}$.

Keywords: Kuwait Environmental Remediation Program, Unexploded Ordinance, Site Soil Characterization, Well Head Pit, Kuwait National Focal Point, Unexploded ordnance.

\section{References}

[1] A. Al-Barood D. Al-Gharabally, H. Al-Qanai, "Kuwait Environmental Remediation Program (KERP): Remediation Demonstration Strategy," in Hong Kong International Conference on engineering \& Applied Science, Kowloon, Hong Kong, 2013.

[2] R. Al-Othman, "Integrated Risk Management for large Soil Remediation under KERP projects," in the $5^{\text {th }}$ International Conference of Renewable Energy and Environment, Spain, Madrid, 2016.

[3] R. Al-Othman, "Guidelines to Review the Quality of Environmental Impact Assessment Report," in the 5 International Conference of Environmental Pollution and Remediation, Spain, Barcelona, 2015.

[4] Soil Remediation Group Media Committee. (2018, April). Soil Remediation. [Online]. Available: http://www.kockw.com/sites/EN/Pages/We\%20Care/Soil-Remediation.aspx 